\title{
ADORNO E HORKHEIMER LEITORES DE FREUD ${ }^{1}$
}

\author{
Verlaine Freitas \\ verlainefreitas@uol.com.br
}

\section{INTRODUÇÃO}

A assim chamada Escola de Frankfurt, que abrigou nomes como Theodor Adorno, Max Horkheimer, Herbert Marcuse e Walter Benjamin, propôs-se uma pesquisa que integrava diversas áreas das ciências humanas, além da Filosofia: História, Sociologia, Psicanálise, Literatura e Ciência Política. Mesmo dentro da pesquisa filosófica, as teorias eram marcadas pela conjunção de várias correntes, como as oriundas de Kant, Hegel, Marx e Nietzsche. Nesse cenário interdisciplinar, a Psicanálise mostra-se fundamental para se compreender a origem e a estrutura argumentativa da obra que se tornou a baliza histórico-filosófica de todo esse movimento teórico: a Dialética do Esclarecimento. Em sua tarefa de refletir de forma radicalmente crítica sobre os motivos que levaram ao surgimento dos regimes nazi-fascistas, Adorno e Horkheimer concebem a história ocidental como um processo em que as diversas formas de racionalidade demonstram sua vinculação íntima com as relações de poder. Das diversas facetas dessa análise, o olhar crítico para a constituição

1. Essa pesquisa recebeu apoio da FAPEMIG (Fundação de Amparo à Pesquisa do Estado de Minas Gerais). 
da subjetividade talvez seja a mais relevante, estando presente em cada uma de suas partes, e é o tema central do primeiro excurso: "Ulisses, ou mito e esclarecimento". Embora a psicanálise não seja a única fonte de apoio conceitual para essa temática ${ }^{2}$, diversos estudos significativos já destacam a inegável importância do pensamento de Freud nas teses principais da Dialética ${ }^{3}$.

O presente texto é constituído de itens temáticos de uma abordagem bem mais ampla que pretendemos trazer a público posteriormente, que almeja fornecer uma visão abrangente da influência freudiana em todos os capítulos, excursos e notas da Dialética do esclarecimento, e, ao mesmo tempo em que faz um comentário que apresenta tal influência, oferece uma crítica interna ao modo como os conceitos psicanalíticos foram abordados. Apesar de sua complexidade temática, e de se ramificar em cada uma de suas aplicações, nossa hipótese de trabalho pode ser agrupada ao redor da ideia de que a apropriação filosófica dos conceitos psicanalíticos por Adorno e Horkheimer dirige-se àquilo que, na obra de Freud, permite-lhes fazer um equacionamento por assim dizer polarizado entre o aspecto repressivo do âmbito social (incluindo os planos econômico, político e cultural) e a dimensão desiderativa somática do indivíduo, elevando essa polaridade a princípio hermenêutico geral em sua crítica ao desenvolvimento histórico da civilização ocidental. Nossa perspectiva, baseando-se em uma crítica de Jean Laplanche (1997) ao que ele denomina "desvio biologizante" da obra freudiana após 1920, pretende apontar para uma insuficiência da apropriação filosófica da psicanálise pelos autores frankurtianos, argumentando que a oposição entre aqueles dois planos caminha no sentido de certa dicotomia, ao não se propor a tarefa de delinear o âmbito da constituição psíquica como tendo uma especificidade e uma dinâmica próprias, não redutíveis ao somático, biológico, mas também não ao linguístico, racional, cultural. Embora essa tese do caráter intermediário do inconsciente não seja propriamente original, pois encontra apoio já em Freud com sua ideia de que a pulsão (fundamento inconsciente de todo o psiquismo) é um

2. Mesmo na interpretação da Odisseia, são decisivas as influências da Fenomenologia do espírito de Hegel e a Teoria do romance de Lukács (cf. GEYER-RYAN \& LETHEN, 1987, p.44ss.).

3. Dentre os vários exemplos, destacaríamos: Joel Whitebook, Perversion and Utopia; Deborah Cook, Culture Industry Revisited. Adorno on mass culture; Karsten Fischer, "Verwilderte Selbsterhaltung"; Konstantinos Rantis, Psychoanalyse und "Dialektik der Aufklärung”; e no Brasil: Sérgio Paulo Rouanet, Teoria Crítica e Psicanálise; Mônica do Amaral: O espectro de narciso na modernidade. De Freud a Adorno. 
conceito limite entre o somático e o psíquico (FREUD, 1999c, p.214) - a qual obteve desdobramento na obra de C. Castoriadis ${ }^{4}$ e Joel Whiebook ${ }^{5}$ -, cremos que nossa formulação avance em pontos significativos, e, concretamente, não vemos essa problemática aplicada ao texto da Dialética do esclarecimento, nem mesmo por Whitebook, cuja obra é citada por Axel Honneth como a mais importante leitura da apropriação da psicanálise pela Teoria Crítica até o momento ${ }^{6}$ - posição com a qual concordamos.

Vale salientar ainda que, com algumas exceções (entre as quais J. Whitebook), as leituras do vínculo entre Freud e Adorno não se apoiam em, nem dialogam com, alguma forma mais recente de teoria psicanalítica. E por que isso seria significativo? Embora encontre muita oposição e crítica, é inconteste que a teoria freudiana é extremamente importante no panorama das ciências humanas. Seu valor, entretanto, está intimamente associado ao modo como seus conceitos, hipóteses e argumentos derivam de certo modo de olhar a clínica, a prática analítica. Não queremos dizer com isso que para comentar textos freudianos seja imprescindível ser analista ou submeter-se a análise, mas sim que é preciso estar muitíssimo atento ao fato de que, nesse âmbito da reflexão teórica, a experiência de tratamento com o desejo do outro adquire uma importância difícil de se superestimar. Assim, o diálogo com autores que têm essa experiência como uma de suas fontes de reflexão é um passo altamente significativo - o que não quer dizer em absoluto que se deva tomá-los como critério de verdade ou algo semelhante (mesmo porque há uma infindável divergência entre as teorias psicanalíticas). Como exemplo desse problema, podemos citar o livro de K. Rantis, acima referido, que, quase sempre quando se refere a Freud, apoia-se em textos básicos de apresentação da teoria freudiana, como o Vocabulário da psicanálise, de Laplanche e Pontalis (que, embora seja uma referência muito útil, e da qual também nos servimos, não traz um desdobramento significativo de vários conceitos). Uma clara exceção a essa nossa crítica

4. Cf. Castoriadis (1975), especialmente o capítulo VI: “L’institution social-historique: l'individu et la chose".

5. Cf. Whitebook (1995), especialmente o capítulo 4: "Linguistic Turn or Bilderverbot?: Wish, Image, and Word in Psychoanlytic Theory”, em que o autor faz uma crítica a Habermas, Lacan, Ricouer e Castoriadis, abordando essa temática da especificidade do inconsciente.

6. No prefácio da coletânea de artigos de Whitebook, Der gefesselte Odysseus, Honneth escreve: "Provavelmente não há hoje [2009 - VF] nenhum outro autor que tenha tentado argumentar sobre a herança psicanalítica da Escola de Frankfurt com maior engajamento e habilidade do que o autor dos artigos aqui reunidos". 
é o livro de Mônica do Amaral, O espectro de narciso na modernidade: de Freud a Adorno (1997), que se vale das teorias de Jean Laplanche e Jacques André para ler a apropriação adorniana da psicanálise. Nossa perspectiva também se vale dessa linha interpretativa, que inclui o psicanalista brasileiro Paulo Carvalho Ribeiro, cujo livro O problema da identificação em Freud. O recalcamento da identificação feminina primária (2001) nos parece o mais avançado de toda essa corrente. Embora o livro de Mônica do Amaral contenha conclusões que subscrevemos, tendo argumentação muito consistente, e se dirija a uma parte importante da Dialética do esclarecimento, não aborda vários outros temas além da problemática da psicologia de massas, presente no capítulo sobre o antissemitismo. É significativo também que a autora, além de não analisar de forma crítica a leitura freudiana de Adorno (no sentido de apontar falhas, inconsistências etc.), passa da perspectiva desse último para a de Laplanche/Jacques André sem problematizar as diferenças entre elas, e para nós essas diferenças são muito significativas para a interpretação do pensamento adorniano. Segundo pensamos, há diversos aspectos da crítica filosófica de Adorno à racionalidade e à sociedade industrial tardia, além de conceitos fundamentais de sua teoria estética, que podem ser analisados de forma bastante nova precisamente com apoio nessa linha interpretativa da teoria psicanalítica.

É preciso ainda ressaltar uma dificuldade conceitual intrínseca a nosso projeto, precisamente em decorrência de nos colocarmos a favor da leitura laplancheana de Freud para interpretar e criticar Adorno e Horkheimer. Com exceção do capítulo "Elementos de antissemitismo: limites do esclarecimento", para a Dialética do esclarecimento, a principal referência psicanalítica é o Freud da assim chamada segunda tópica, após 1920, com especial foco no Mal-estar na civilização. Entretanto, tal como aludimos brevemente acima, compartilhamos com Laplanche a ideia de que esse período da produção freudiana demonstra um retrocesso em relação a diversos princípios teóricos anteriores, em que a sexualidade inconsciente, constituída durante a formação egóica na primeira infância, possuía uma relevância e um papel teórico que a dualidade entre pulsão de vida e de morte irá deslocar de forma enfática. Desse modo, precisamos deixar clara ao leitor nossa escolha pelo Freud da primeira tópica como ponto de apoio para a leitura da Dialética do esclarecimento, embora não haja espaço aqui para fundamentar tal opção. 
Tal como vemos nos "Protocolos das discussões sobre alteração funcional de conceitos "burgueses"' 7 , o projeto interdisciplinar da Teoria Crítica é fazer uma reinterpretação dialética de temas, noções e hipóteses da psicanálise (e de outras ciências), inserindo-os em uma compreensão histórico-filosófica da realidade do capitalismo tardio. Isso mostra que não se pretende manter no mesmo plano de abstração/especificidade da psicanálise, além de fazer-lhe várias críticas. Nossa exegese não consistirá em apenas mostrar a derivação psicanalítica de alguns conceitos na Dialética do esclarecimento, mas sim em investigar em que medida e de que forma a concepção psicanalítica manteve ou não sua força e conteúdo de verdade (para usar um mote adorniano) ao passar para o plano de análise histórico-filosófica da realidade cultural do ocidente.

Dada a grande complexidade e variedade de aspectos da influência da teoria freudiana na Dialética do esclarecimento, e tendo em vista o escopo de apresentar alguns elementos de nossa leitura, fazemos a seguir um apanhado de um tema relevante em cada parte da Dialética, para exemplificar e demonstrar os princípios de nossa investigação.

\section{A ANGST ${ }^{8}$ NO "CONCEITO DE ESCLARECIMENTO"}

A compreensão da metamorfose do mito nos processos sucessivos de racionalização, tal como Adorno e Horkheimer a veem, fundase na perspectiva dialética de como a subjetividade se defronta com a alteridade, marcando-a pela violência ao se impor na objetividade social dos processos de subjetivação. O lastro social do modo como cada indivíduo erige sua identidade gira ao redor do fulcro estabelecido pelas redes subterrâneas de poder e explicitamente cristalizadas na relação do sujeito com os demais, consigo mesmo e com a realidade objetiva. Segundo

7. Trata-se de uma compilação de discussões entre membros do Instituto de Pesquisa Social, e as que serviram de referência para nossa pesquisa se deram entre Horkheimer e Adorno em 1939; o texto foi incluído nos Gesammelte Schriften de Horkheimer, vol.12, pp.436-58.

8. A palavra Angst em alemão pode ser perfeitamente traduzida ou por "medo" ou por "angústia”. Tal como veremos mais à frente, nessa última possibilidade, tratar-se-ia de um medo sem objeto definido - o "medo neurótico", que pode transformar-se em fobia, complexo sintomático da assim chamada "histeria de angústia" - tal como analisado longamente por Freud nas Conferências Introdutórias à Psicanálise, conf. XXV. Como a oscilação entre os dois conceitos é grande, dentro às vezes de um mesmo parágrafo, tanto em Freud quanto em Adorno, preferimos usar a palavra alemã, sem traduzi-la. 
os autores, a Angst é um móbil subjetivo que nutre profundamente os fios sociais que deturpam a visão que todos poderiam ter da utópica diferença para com aquilo que a realidade sócio-empírica sedimentou na mente de todos - dominados e dominantes: "O esclarecimento é a Angst mítica que se tornou radical" (DA, p. $3^{9}$ ). Análogo a como o esclarecimento [Aufklärung] não seria uma designação relativa a um período histórico (o assim chamado "Iluminismo"), a Angst não seria apenas um sentimento entre outros no plano individual: "mais essencial [do que o interesse individual de ganho - VF] como motivo subjetivo da racionalidade é a Angst. Ela é mediada [socialmente - VF]" (ADORNO, 1997i, 46-7). Desde as primeiras formas de decantação objetivante da dispersão dos fenômenos naturais em deuses e forças mágicas, até a atmosfera de opressão nos regimes totalitários e de exclusão social nas diversas sociedades democráticas, a Angst se mostra um índice do poder de alienação coletivo consubstanciado como princípio de adequação do indivíduo a uma totalidade a que se deve conformar e dela retirar forças para perseverar na existência.

A Angst é também muito referida por Adorno em outros textos, e são significativos para nós os (raros) momentos em que ele fala do que poderia superar o estado de falsidade reinante na sociedade maciçamente impregnada pelas relações abstratas de troca: "O sujeito cognoscente deve admitir os limites que lhe são impostos objetivamente e que colidem com seu direito à autoconservação e felicidade, e não se comportar como se fosse um ser humano do tipo que talvez se realize somente no estado de liberdade, portanto sem Angst" (ADORNO, 1997c, p.778); "A capacidade para a Angst e para a felicidade são a mesma abertura ilimitada e elevada até a auto-renúncia - para a experiência, em que o fracassado se reencontra" (ADORNO, 1997e, p.228). Igualmente enfático é Horkheimer, quando diz: "o ser humano realiza-se apenas como Angst" (HORKHEIMER, 1985, p.451).

O motivo que nos levou a não traduzir a palavra Angst é índice de algo de suma importância conceitual. Em Freud, temos uma divisão claramente estabelecida entre a angústia-real e a angústia neurótica. A primeira, que coincide com medo (Furcht, em alemão, próximo a Schreck, pavor, susto), possui um objeto real a se temer, de tal forma que o afeto, na medida em que é elemento motivacional para a fuga ou proteção,

9. As referências à Dialética do esclarecimento (Dialektik der Aufklärung - DA) serão feitas a partir do texto presente em Gesammelte Schriften de Adorno, vol. 3, editadas pela editora Suhrkamp (cf. referências bibliográficas ao final para detalhes). 
pode ser considerado normal. A segunda, por sua vez, ou ocorre de forma desmesurada em relação ao um perigo não tão grande, ou se dá em relação a coisas que não oferecem perigo objetivamente verificável (cf. FREUD, 1999f, p.413 $)^{10}$. Esta última, na medida em que aponta para a constituição psíquica neurótica/normal ${ }^{11}$, sempre se associa a uma realização de desejo, ou seja, a uma satisfação pulsional, no limite, a um gozo: "A Angst, que significa uma fuga do eu para longe de sua libido, segundo se supõe, deriva, em última análise, dessa mesma libido" (FREUD, 1999f, p.420). A Angst surgiria em virtude do caráter insuportável do afluxo afetivo ligado a um complexo fantasístico inconsciente, cuja dinâmica, intensidade e valor representacional colidem frontalmente com estratos egóicos menos e mais profundos, de modo que o quantum de afeto inconsciente afluiria sem a mediação suavizante da censura, emergindo como que em curtocircuito. O excesso pulsional, fator substantivo para a caracterização dos mecanismos de defesa egóicos perante o inconsciente, caminha rumo à situação de transbordamento, instante em que a dimensão aflitiva do conflito psíquico demanda formações de compromisso cuja urgência é proporcional à cegueira com que são realizadas.

E em Adorno e Horkheimer? - qual das duas Ängste está em jogo? Para Konstantinos Rantis, não há dúvida: "Na Dialética do esclarecimento trata-se de uma angústia real, que concerne à própria existência - a existência natural e a possibilidade da auto-conservação" (RANTIS, 2001, p.45). É certo que na maior parte das vezes a Angst é tratada como medo, pavor, terror, de modo que até em uma mesma frase são usadas as três palavras, Angst, Schreck e Furcht, sem distinção significativa. Entretanto, o que dizer do emprego de Angst na seguinte passagem: "A Angst de perder o próprio eu e com ele suprimir a fronteira entre si e o outro, o temor (Scheu) perante a morte e a destruição, está irmanada a uma promessa de felicidade pela qual a civilização foi ameaçada a cada instante" (DA, p. 51). Em termos semânticos, não há dúvida que a palavra

10. Cf. também o comentário de Laplanche sobre a diferença entre angústia e medo (cf. LAPLANCHE, 1998a, p.55 ss.), em que o último é visto como reação a um perigo objetivamente detectado, enquanto a outra seria um terror difuso, em que a origem do "medo" se deveria procurar nas formas de constituição subjetiva: fantasias, traumas, desejos inconscientes.

11. Aqui assumimos a já clássica ideia de Freud de que a diferença entre a condição normal e a neurótica se dá apenas em termos de graus e formas com que se formam soluções de compromisso entre desejos inconscientes e as diversas formas de censura, de modo que não haveria distinção qualitativa estrita entre a neurose e a normalidade. (Cf. FREUD, 1999a, pp.203-204) 
deve ser traduzida por "medo", tal como o faz Guido de Almeida em sua excelente tradução dessa obra. Entretanto, em termos conceituais, o fato de os autores dizerem que a Angst se irmana a uma promessa de felicidade, que surge precisamente como uma ameaça para a integridade do eu, não deixa dúvida de que temos uma forte aproximação com a ideia freudiana de Angst como resultado da ameaça pulsional transbordante. Ora, é exatamente essa concepção da mescla entre medo e um gozo dilacerante para o eu que serve de base para a toda a leitura de Adorno e Horkheimer sobre a Odisseia. Mas, por outro lado, na maior parte do primeiro capítulo da Dialética do esclarecimento a Angst é realmente tratada sem essa ambiguidade. O mana, o espírito que move, o poder infinito e difuso da natureza, será referido pelos autores como fonte de um terror indescritível, em relação ao qual o grito se cristaliza como nome da própria coisa (cf. DA, p. 31).

Não será o caso de questionar em que medida se trata apenas de medo? Não será o caso de dizer que esse poder infinitamente ameaçador não seria, por sua vez, fonte de uma comoção arrebatadora, de uma excitação radicalmente incompreendida? Em outras palavras: não será a experiência de encontro com ele a ocasião em que uma espécie de gozo ameaça por dentro proporcionalmente a como o perigo é vivido de fora? Essa é, naturalmente, a nossa posição, que aqui podemos apenas indicar. - No entanto, seria muito a propósito dizer que nem mesmo precisamos recorrer aos conceitos psicanalíticos para apoiar nossa leitura crítica, pois podemos fazê-lo através do conceito hegeliano de arte simbólica, das civilizações arcaicas, anteriores à grega, em que o colossal, gigantesco, assombroso, demonstra uma inadequação da Substância perante o humano, mas que nem por isso é apenas fonte de terror, pois incluía também uma forma de prazer, que Kant chamou de "prazer negativo" ao falar do sentimento do sublime (HEGEL, 2001, p.392ss.; KANT, 2001, §23).

\section{A AUTO-CONSERVAÇÃO NO "EXCURSO I: ULISSES, OU MITO E ESCLARECIMENTO"}

A epopeia homérica participa do processo de esclarecimento, na medida em que demonstra certa consciência do distanciamento do sujeito perante o âmbito natural, que era incipiente no registro da apropriação mítica das forças naturais. A figura do herói que se perde para se ganhar (cf. DA, p. 74) funda-se na rigidez da consciência da unidade de si ao negar abstratamente a multiplicidade da natureza que 
se tem que atravessar ${ }^{12}$. As inúmeras aventuras ulissianas são metáforas da alteridade que ameaça na proporção com que promete ilusoriamente uma fusão com a natureza. A fuga do sujeito perante as potências míticas de dissolução, representantes da inevitabilidade do destino, corresponde ao esforço civilizacional de negação do mito. Frente ao entrelaçamento funesto da ciclicidade indefinida da natureza e o horror estampado na remissão de todo ser e acontecer a uma origem ancestral, o relato homérico testemunha a consciência patriarcal do engodo presente em todo sacrifício, em que o princípio da troca, que faz com que desiguais sejam abstratamente nivelados, se mostra como a célula da irracionalidade da razão esclarecida que vige até os derradeiros momentos do capitalismo atual: a violência com que o universal se impõe na clareza ofuscante do real positivamente verificado em sua factualidade inconteste. O sacrifício que enrijece o eu se faz à sombra da crescente lucidez de que a unidade coletiva se constrói ao negar o sacrifício imposto pela natureza. Desse modo, "a história da civilização é a história da introversão do sacrifício. Em outras palavras: a história da renúncia” (DA 73).

Essa última ideia ressoa de forma clara o princípio teórico seguido por Freud, não apenas em $O$ mal-estar na civilização - referência central para os argumentos na Dialética do esclarecimento -, mas também em textos anteriores, como "Moral sexual civilizada e doença nervosa moderna" e Totem e Tabu, em que a Cultura é concebida como resultado da confluência da energia psíquica pulsional represada. A satisfação dos desejos individuais é sistematicamente frustrada em decorrência da luta contra as necessidades objetivas da conservação da vida societária. Tendo como plano de fundo o conflito subjetivo entre forças pulsionais antagônicas, a civilização se mostra como essencialmente recalcitrante ao desiderato de harmonizar os planos individual e coletivo, gerando

12. Klaus Baum diz de Ulisses, ao se atar ao mastro do navio para resistir à sedução do canto das sereias, que "a astúcia que se exprime em sua prisão é negação determinada do poder do canto e, ao mesmo tempo, condição para a ruptura intensa, dolorosa, entre a ânsia e o ímpeto para sua satisfação" (BAUM, 1988, p.67). O comentador considera que a negação do desejo do herói somente seria abstrata se ele tapasse totalmente os ouvidos com cera, do mesmo modo que seus companheiros - posição com a qual concorda Rodrigo Duarte (1993, p.93). Ora, muito do sentido do Excurso I consiste em mostrar que a astúcia ulissiana consiste em praticar uma violência a todo ímpeto desiderativo, à "natureza interna", seguindo a obstinação autoconservadora fundada em sua racionalidade esclarecida. Para ser abstrata, a negação não precisa ser absoluta, pois basta que ela negue o que há de verdadeiro, legítimo, na alteridade. Cf. nossa tese de doutorado (FREITAS, Inédito, p.94 ss). 
a infelicidade sempiterna que se associa ao progresso como seu preço inalienável.

À diferença de Freud, entretanto, Adorno e Horkheimer conferem uma quase exclusividade à renúncia [Entsagung], em detrimento da frustração [Versagung], como âncora do móbil subjetivo que conecta o indivíduo à sociedade e que o faz assimilar a objetividade social como seu constituinte, e isso é algo que aponta para o maior peso do conflito entre indivíduo e sociedade do que dele consigo mesmo. A primeira, Entsagung, caracteriza-se por uma recusa do objeto imposta ao desejo, seja pelo próprio indivíduo, seja pelo outro (família, sociedade), enquanto a segunda, Versagung, mais afeita a processos inconscientes, indica uma falha na assimilação do objeto pelo sujeito como fonte de satisfação, de tal forma que poderia ser causada não apenas pela recusa, mas paradoxalmente - pelo excesso do objeto, ou seja, pelo afluxo excessivo de investimento afetivo causado por este. Como dizem Laplanche e Pontalis, "o que está em jogo é menos a falta de um objeto real do que a resposta a uma exigência que implica um determinado modo de satisfação ou que não pode receber satisfação de nenhuma maneira" (LAPLANCHE \& PONTALIS, 2000, p.204). ${ }^{13}$

Dos vários aspectos que podemos abordar de forma crítica, ressaltamos que a apropriação dos conceitos psicanalíticos de Adorno e Horkheimer em sua Urgeschichte der Subjektivität (história primeva da subjetividade) abstrai sistematicamente a problematização de princípios de subjetivação em que a autoconservação seja posterior ao teor conflituoso da psique. Embora essa seja uma problemática muito complexa para ser tratada em tão pouco espaço, dizemos, seguindo J. Laplanche, que o princípio de autoconservação não toma parte no conflito psíquico (LAPLANCHE, 1985, p.55), de forma que é necessário conceber-se o eu como ligado, em sua raiz mais remota (na ontogênese), a algo que nega e afirma o eu, aquém do ímpeto da autoconservação. Haveria, por outro lado, uma resposta para esse aporte crítico, na medida em que a autoconservação fosse tomada não somente como princípio geral da vida, e da humana em particular, mas também, de forma mais específica, da própria constituição do eu, tal como o faz K. Rantis

13. É preciso ressalvar que Freud também se refere em grande medida à Entsagung ao falar da relação entre indivíduo e sociedade, e é um dos pontos de apoio nodais no Malestar na civilização. Apesar disso, vemos como diferença substantiva para com Adorno e Horkheimer o fato de que nos textos freudianos a falha de assimilação do objeto pelo sujeito é intrinsecamente constitutiva do desejo, algo como que inalienável deste; cf. Laplanche \& Pontalis (200o), verbete "Frustração". 
(2001, p.118). Entretanto, há uma enorme diferença entre os planos da conservação da vida: (1) na natureza; (2) no indivíduo em sociedade; (3) e na dinâmica psíquica. Levando em conta apenas esses dois últimos, dizemos que, no indivíduo como um todo, a autoconservação é um resultado, um desaguadouro de um complexo de forças (uma solução de compromisso), enquanto na vida intrapsíquica a unidade do eu é um princípio de estruturação cuja dinâmica pode desafiar nuclearmente o da autoconservação vital da individualidade como um todo. Os processos de investimento afetivo no eu, narcísicos, são por demais conflituosos, sujeitos a contradições inassimiláveis ao desiderato de autoconservação tal como vemos utilizado por Adorno e Horkheimer na Dialética do esclarecimento. ${ }^{14}$

\section{O PROBLEMA DA REIFICAÇÃO NO “EXCURSO II: JULIETTE, OU ESCLARECIMENTO E MORAL”}

Nesse excurso, Kant, Nietzsche e Marquês de Sade têm seus escritos morais analisados tendo em vista a consumação do esclarecimento no âmbito da relação entre espírito e natureza, em que os valores éticos e a racionalidade por um lado, e os prazeres e a corporeidade, por outro, demonstram uma vertiginosa anulação do âmbito propriamente humano, de mediação entre tais planos. De forma um tanto surpreendente, tanto o imperativo categórico kantiano, quanto o Übermensch ("além-dohomem", "super-homem") nietzscheano, quanto a apologia do prazer libertino em Sade são índice de um processo radical de reificação, em que os ditames racionais de negação dos interesses patológicos, de anulação da posição compassiva perante o outro e de maximização do aproveitamento de todas as formas de prazer assimilam como que em curto-circuito a natureza e a racionalidade. O medo ancestral de recaída na natureza compele à negação abstrata de toda forma de alteridade que seja índice do que a civilização se esforça continuamente por esquecer. Para Adorno e Horkheimer, a esfera do sentimento é a que configura o espaço em que tal polaridade pode ser pensada de forma mediada. $\mathrm{Na}$

14. A melhor caracterização do teor conflitivo da constituição egóica como fundamento originário da subjetividade nos parece sem dúvida a fornecida por Paulo Carvalho Ribeiro em seu livro O problema da identificação em Freud. O recalcamento da feminilidade primária; cf. especialmente o capítulo 7, "Em busca de uma metapsicologia à altura das psicoses". 
dimensão erótica, por exemplo, em vez da ilusão de um amor purificado, os autores frankfurtianos insistem na metamorfose sublimada de ímpetos sexuais violentos, e no lugar de uma atratividade puramente física, temse "imagens em que toda a experiência social está contida" (DA, p. 128).

Sobre essa parte do texto, nossa análise, seguindo um texto que já publicamos (FREITAS, 2009), aborda de forma crítica o conceito extremo de reificação que se depreende da crítica aos três autores analisados. O caráter hiperbólico de tal conceito pode ser visto em várias partes desse Excurso, tais como: “o pensamento torna-se totalmente um órgão, é rebaixado à natureza” (DA, p. 106); “a razão pura tornou-se desrazão, um procedimento sem erro e sem conteúdo" (DA, p. 110); “o colosso a-consciente [bewußtlose] do real, o capitalismo desprovido de sujeito, exerce a aniquilação cegamente" (DA, p. 134). Nossa crítica é a de que essa concepção toma como real aquilo pelo que o pensamento dominador gostaria se passar: algo radicalmente desprovido de subjetividade. De um ponto de vista filosófico que se nutra de conceitos psicanalíticos, é preciso investigar o quanto a racionalidade supostamente reificada ao extremo deve ser vista como uma reação desesperada ao núcleo pulsional inconsciente vertiginosamente conflituoso e ameaçador. Sendo fruto de uma atitude reativa diante de ímpetos pulsionais, a reificação - analisada sob as figuras da formalização racional em suas diversas facetas - deve ser pensada como expressão de um desejo, e não como a simples negação de todo desejo. Um dos grandes problemas que pensamos permear toda a análise filosófica da Escola de Frankfurt sobre o desenvolvimento da racionalidade ocidental consiste em que ela considera a opressão social - e sua internalização pelos indivíduos em seus valores essencialmente como negação, anulação, dos desejos e dos prazeres. A esse respeito, é instrutiva a diferença entre as análises sobre Kant e Sade feitas por Adorno/Horkheimer e por Lacan, uma vez que a crítica dos frankfurtianos enfoca exclusivamente a negação apática e opressiva do prazer nos ímpetos corporais, ao passo que para o psicanalista francês, como bem resume Lisa Yun Lee, "em vez de eliminar todo gozo patológico de formulações éticas [...] o sistema ético kantiano reflete-o e desloca-o para a força imperativa das máximas formais" (LEE, 2005, p.35) ${ }^{15}$. Discordamos da comentadora, entretanto, quando ela enfatiza mais as semelhanças do que as diferenças entre Adorno/Horkheimer e Lacan, pois essa diferença é índice muito importante de um fundamento para toda a concepção da Teoria Crítica sobre a sociedade.

15. A análise de Lacan sobre a relação entre Kant e Sade encontra-se em Lacan (1999, pp.243-269). 


\section{A (IN)DIFERENÇA ENTRE REPRESSÃO E RECALQUE NA "INDÚSTRIA CULTURAL. ESCLARECIMENTO COMO MISTIFICAÇÃO DAS MASSAS"}

Emsuacríticaaos produtosdaindústriacultural,AdornoeHorkheimer negam reiteradamente a ideia dos produtores culturais de que o sucesso de seus empreendimentos se deve ao fato de que as pessoas gostam do que lhes é oferecido. Muito do esforço teórico dos autores consistirá em demonstrar como o peso próprio do meio técnico, o entrelaçamento dos diversos produtos, em que se forma uma teia de estereotipias que condicionam a percepção hipersaturada dos espectadores, faz com que os consumidores sejam muito mais objetos do que sujeitos frente à cultura de massa (cf. DA 167ss.). Dos diversos elementos dessa estratégia de assujeitamento da percepção pelo aparato industrial, ressaltamos a diferença existente entre o caráter pornográfico e puritano da cultura de massa e do ascetismo sem pudor da arte: a primeira sempre estimula o desejo, excitando o prazer preliminar não sublimado, mas ao mesmo tempo recusa sua realização concreta, colocando o sujeito em um ritual de Tântalo, eternamente acossado por seu objeto de desejo e sempre frustrado. Por sua vez, a obra de arte, embora também se recuse a figurar a plenitude do objeto de desejo, não engana quanto à possibilidade de sua realização. Em outras palavras, tanto a indústria cultural quanto a arte acabam sendo uma espécie de promessa, mas no primeiro caso, uma vez que a realização do desejo é acintosamente figurada de forma positiva, tem-se uma espécie de estelionato, um logro, uma mentira escancarada acerca da inesgotabilidade do desejo, que aparece como que magicamente suprimida na positividade deslumbrante que o objeto adquire na técnica publicitária, no glamour das estrelas de Hollywood etc. A partir da formulação de Stendhal, bastante recorrente na Teoria Crítica, de que "a beleza não é mais do que a promessa de felicidade" (STENDHAL, 1857, p.34), Adorno e Horkheimer caracterizam a sublimação estética como consistindo nesta assunção da impossibilidade de realização do desejo. Assim, a arte, assumindo a si mesma como promessa, não iludindo quanto à positividade do objeto de desejo, resgata a dignidade da pulsão, humilhada pela renúncia ao objeto de desejo, uma vez que a recusa à satisfação imediata é negada dialeticamente na força com que a reconciliação com o objeto é colocada em jogo (cf. DA, p. 161-162).

Embora essa concepção seja muito rica para entendermos tanto o processo de alienação desiderativa do consumidor da indústria cultural quanto o processo sublimatório na arte, percebemos uma questão relevante quando é dito que a pulsão é humilhada em virtude de sua 
frustração [Versagung], da negação de seu objeto de desejo. A partir da corrente interpretativa do pensamento de Freud em que nos apoiamos, podemos dizer que o teor contraditório do núcleo inconsciente do psiquismo faz com que a negação pulsional do desejo seja intrínseca a este, de modo que há uma impossibilidade por princípio de satisfação com objetos de desejo. A ideia de uma pulsão humilhada pela ausência do objeto ecoa em outras várias formulações adornianas, em que pesa muito mais um conflito entre o desejo e a realidade externa, do que um conflito intrapsíquico, e a opção por uma das duas perspectivas tem implicações importantíssimas nos âmbitos moral e estético. Veja-se, a esse respeito, Minima Moralia, §136, em que o "conflito" é explicitamente do desejo com a realidade, e não deste consigo mesmo: "os artistas manifestam instintos violentos, de tipo neurótico, que eclodem livremente e, ao mesmo tempo, colidem com a realidade”; também a Dialética negativa, em que se lê que "junto com a repressão externa desapareceria, provavelmente depois de longo tatear e sob ameaça permanente de recaída, também a interna" (ADORNO, 1997f, p.261), como se se pudesse conceber um ser humano sem a contradição interna, que, em vez de "repressão", refere-se muito mais a "recalque" ${ }^{16}$. Além disso, vemos em várias passagens, como no excurso sobre Ulisses, que a diferença entre recalque e repressão fica ainda mais diluída quando essa temática abrange a ideia de opressão, em que a exterioridade social ganha um peso tal que tende a retirar de cena a questão do conflito intra-psíquico, que tendemos a considerar como fundamento para se compreender a ligação do sujeito perante o âmbito coletivo.

Por outro lado, há vários momentos na obra de Adorno em que se pode ver sua insistência em não assimilar a dinâmica psíquica à social, e esse é o mote de sua crítica aos revisionistas freudianos (especialmente Karen Horney, mas também Erich Fromm), que subsumem apressadamente o indivíduo à coletividade (ADORNO, 1997g, p.20ss.). Tal como diz Deborah Cook, para Adorno, a sociedade não simplesmente reprime

16. Há que se salientar que repressão e recalque, para os quais há palavras distintas em alemão, Unterdrückung e Verdrängung, são virtualmente igualados nos textos de autores ingleses, na medida em que "repression" é usada muitas vezes para ambos os conceitos, não se tomando o cuidado de usar "supression" para traduzir Unterdrückung e "repression" para Verdrängung (estratégia usada por James Strachey em sua tradução canônica da obra completa de Freud em inglês, de 1966). Essa crítica vale até mesmo, e de forma clara, para Marcuse (cf. LAPLANCHE, 1992b, pp.59-88 e FREITAS, 2007, pp.1-9), e, segundo pensamos, também para Adorno. Para uma apresentação didática e clara dessa diferenciação, cf. Laplanche \& Pontalis (2000), verbetes "Recalque ou recalcamento" e "Repressão". 
os indivíduos, mas se serve das leis implacáveis do inconsciente para subjugá-los (COOK, 1996, p.51ss). O grande problema é que Adorno não se deteve com clareza no delineamento dessa dimensão intrapsíquica individual, e, como dissemos, tende a diluir conceitos que seriam cruciais para tanto, como a relação recalque-repressão-opressão, em uma concepção filosófica "macro" da realidade histórica.

\section{MÓBIL PSÍQUICO E “ELEMENTOS DO ANTISSEMITISMO. LIMITES DO ESCLARECIMENTO”}

Essa parte da Dialética do esclarecimento contém, junto com o excurso sobre a Odisseia, muitos conceitos, temas e argumentos oriundos da teoria freudiana: a psicologia das massas, tal como desenvolvida por Freud em Psicologia de grupo e análise do ego; a concepção dos mecanismos da formação paranóica, que inclui os importantes conceitos de projeção e defesa psíquica; a teoria do narcisismo; as hipóteses freudianas sobre o anti-semitismo, tal como exposto em Moisés e o monoteísmo, entre outros $^{17}$. Aqui nos deteremos na última seção, VII, onde os filósofos de Frankfurt abordam a mentalidade do ticket, em que o pensamento se guia em bloco por um círculo de opções que predeterminam a escolha segundo modelos gerais de mentalidade. De início, os autores reafirmam uma ideia presente no segundo Excurso e também no capítulo sobre indústria cultural: o sistema da sociedade capitalista expropria os indivíduos da tarefa de mediação cognitiva entre o âmbito abstrato, racional, e a particularidade concreta, sensível: "a intuição cega e os conceitos vazios são reunidos rigidamente e sem mediação” (DA, p. 228). Essa perspectiva, de cunho epistemológico, é transposta para o âmbito econômico, em que a pequena empresa é substituída pela grande loja de departamentos, e daquele para a economia pulsional dos indivíduos, cuja "pequena empresa psicológica" cede lugar à indústria cultural, aos gerentes de multinacionais, aos comandos políticos etc. Tal como no âmbito cognitivo, o juízo já não é realizado pelo indivíduo, no âmbito desiderativo as instâncias psíquicas (id, ego e superego) foram expropriadas, de tal sorte que o funcionamento da aparelhagem econômica não seja perturbado pela individuação, por mais dócil que

17. Na verdade, a presença da psicanálise é tão expressiva em suas hipóteses sobre o antissemitismo, que Adorno teve que se defender das críticas de "psicologismo", reafirmando, entretanto, a importância da psicanálise nesse complexo teórico (cf. RANTIS, 2001, p.127-8 e ADORNO, 1997j, p.371). 
esta seja. Essa temática se liga à importante tese da Teoria Crítica da sociedade sem o pai, em que se diz que com a redução da autonomia do pequeno empreendedor burguês, sua concomitante assimilação pelas grandes corporações, e ainda seu anonimato das relações no mercado de trabalho, cada vez mais a autoridade paterna deixou de ser uma referência para a constituição egóica robusta dos filhos. Na célula familiar do capitalismo inicial, o pai, ao mesmo tempo fonte de interdições e admiração, ainda propiciava uma forma de mediação substantiva frente à influência dos poderes socialmente instituídos. Com a redução drástica desse apoio da formação psíquica no núcleo familiar burguês, o superego individual tende cada vez mais a se enfraquecer (gerando indivíduos dóceis ao sistema e/ou autoritários): "junto com a família desapareceu, enquanto o sistema subsiste, não apenas a agência ativa da burguesia, mas também a resistência, que, é verdade, reprime o indivíduo, mas também o fortalece, se é que não o produz. O fim da família enfraquece as forças de oposição" (ADORNO, 1997e, p.23) ${ }^{18}$.

O delírio persecutório fascista está essencialmente fundado nessa reificação exacerbada, densa e inexpugnável em "que toda espontaneidade e mesmo a simples ideia do verdadeiro estado de coisas tornou-se necessariamente uma utopia extravagante, um sectarismo desviante" (DA, p. 231). Apesar de dizer que os indivíduos não desapareceram juntamente com seus determinantes psicológicos, Adorno e Horkheimer enfatizam que todo traço de individualidade, incluindo os sintomas neuróticos, está adaptado ao funcionamento plenamente reificado do sistema (cf. DA, pp. 231-232).

Mais uma vez, é preciso reconhecer que se trata de uma temática complexa ao extremo, mas gostaríamos de colocar brevemente o princípio de nossa abordagem crítica: tanto a ideia de expropriação do pulsional e do esquematismo pela cultura de massa, quanto a de reificação presente no Excurso II, caminham, segundo pensamos, no sentido de conceber o infortúnio da alienação da guerra, das exclusões de minorias, da opressão social etc., apenas de forma exógena, ou seja, da sociedade para os indivíduos. Em um importante texto sobre essa problemática, Adorno inicia dizendo que dificilmente as massas se deixariam levar pelas grotescas e falsas propagandas "se não houvesse nelas [nas pessoas - VF] algo que correspondesse às mensagens de sacrifício e vida perigosa" (ADORNO, 1997i, 42). Entretanto, vemos que cada vez mais esse "algo" interno, na verdade, é plenamente herdeiro

18. Para uma apresentação panorâmica desse tema e de questões correlatas, cf. Cook (1996, p.13oss). 
do mesmo plano de onde provêem tais mensagens, ou seja, as potências desprovidas de subjetividade da realidade social reificada. Na seção VII que comentamos, vemos escrito de forma bastante enfática: "é só quando a total identificação com essas potências monstruosas é impressa na multidão concernida como uma segunda natureza, e todos os poros da consciência são tapados, as massas são conduzidas a uma forma de absoluta apatia, que as capacita a realizações assombrosas" (DA, p. 230 - grifos nossos).

Coloquemos nossa perspectiva em forma de questões: será que não haveria princípios de subjetivação, de constituição da subjetividade, que seriam anteriores (em termos lógicos, ou seja, como fundamento ou condição de possibilidade) às diversas formas de socialização? - Dito de outra forma: será que toda forma de culturalização não encontraria móbeis de constituição psíquica sobre os quais deveria agir - canalizandoos, modelando-os - e neles se apoiar, mas que não seriam eles mesmos moldáveis pela cultura em seu princípio mais fundamental? Nesse sentido, se respondermos afirmativamente a tais indagações, podemos dizer que toda e qualquer sociedade sempre incita, fomenta, "produz" infinitos desejos, mas nenhuma cria, forja, princípios de estruturação psíquica dos desejos.

De sumo interesse para essa temática é uma passagem das Preleções sobre história e liberdade, em que Adorno, ao falar da assimilação do movimento objetivo e universal da história pelos indivíduos, pergunta se

aqui não vigoraria uma dialética no sentido de que, para que essas relações hierárquicas se sedimentem nas formas subjetivas, sempre ao mesmo tempo tenha que existir um momento na subjetividade constituinte, o qual, por sua vez, contribui para que tal seja experienciado assim e não de outra maneira uma pergunta extremamente complexa, que eu agora apenas lhes indico, mas de forma alguma quero responder (ADORNO, 2006, p.91).

Em momentos posteriores das Preleções, o autor procurará responder a isso de uma ou de outra forma, as quais não podemos investigar aqui. Interessa-nos especialmente o fato de que, na Dialética do esclarecimento, essa problemática constitui uma importantíssima lacuna, pois se tais princípios da subjetividade constituinte "existem", é pelo menos possível que a sociedade não necessite, por um lado, de uma reificação extrema e, de outro, de "tapar todos os poros da consciência individual”, expropriando os indivíduos de seus componentes psíquicos, para que os infortúnios da racionalidade ocidental sejam compreendidos em um dos aspectos cruciais de sua dinâmica subjetiva. 


\section{CORPO, DESEJO E FANTASIA NAS “NOTAS E ESBOÇOS”}

Por fim, vejamos um dos ensaios dessa parte da Dialética, "Interesse pelo corpo", bastante significativo para nossos propósitos, em que o amor-ódio pelo corpo é analisado com base em uma ideia de vínculo recalcado pela cultura em relação à corporeidade. $\mathrm{O}$ mote conceitual dos autores é a anulação do corpo vivo [das Leib], transformado em um corpo inerte, reduzido à sua materialidade [der Körper], devido à fúria com que virtualmente todas as formas de cultura insistem em negar o diálogo entre Espírito e Natureza. Ao mesmo tempo objeto de profundo desejo, mas de recusa em diversas formas ideológicas de rebaixamento e mortificação/martírio, o corpo vivo mostra o quanto a cultura reificada não tolera a multiplicidade não-reduzida, mediada, de uma parte da natureza que relembra à civilização o quanto esta - somente de forma ilusória e ideológica - é capaz de anular seu oposto. Apoiando-se em uma passagem do Mal-estar da civilização de Freud, em que este lança a hipótese de um recalcamento orgânico do prazer olfativo - quando o homem se afastou da zona erógena feminina em virtude de sua posição ereta (FREUD, 1999d, pp.458-9) -, Adorno e Horkheimer vão dizer da origem do mal radical, ou seja, "o assassino, o homicida, os colossos animalizados, [...] os linchadores e os membros da Ku-Klux-Klan" (DA, p. 268), a partir dessa relação rancorosa frente à natureza interna: "neles o amor-ódio pelo corpo é bruto e imediato, eles profanam tudo o que tocam, aniquilam tudo o que veem à luz, e este aniquilamento é o rancor pela reificação, eles repetem em fúria cega no objeto vivo o que eles não mais podem fazer desacontecer: a cisão da vida no espírito e seu objeto" (idem). A crueldade seria uma "rebelião não-sublimada e, no entanto, recalcada da natureza condenada" (DA, p. 269).

Aqui, de forma análoga ao que dissemos de forma crítica em relação à Angst e também ao conceito de reificação, valeria a crítica de que o léxico dos autores não mobiliza conceitos que indiquem o comprometimento subjetivo do agente em termos de um investimento afetivo nas ações más. A ideia de que a maldade seja índice de retorno vingativo da natureza é por demais abstrata, como uma Weltanschauung, para ser usada para esclarecer móbeis subjetivos individuais. Em nenhum momento dessa descrição vemos algo próximo de um gozo pelo mal, mas sim princípios despersonalizados, des-subjetivados, como "fúria cega" e "vingança da natureza”; e também se fala da crueldade, da barbárie, do morticínio, sem colocar em jogo elementos conceituais aplicáveis à dinâmica de constituição individual do desejo: todo assassino teria a mesma forma e grau de rancor pela separação espírito/natureza? A natureza que se 
vinga em cada genocida o faz em função de que processo de constituição subjetiva individual? - ou seria a "mesma" natureza vingativa exercendo um poder universal?

A partir de uma elaborada leitura crítica de Jean Laplanche ao pensamento freudiano, vemos que o desejo inconsciente - fruto da emergência precoce da sexualidade - é sempre mediado por fantasias inconscientes, de modo que o corpo atrai ou repele em virtude de tal mediação ${ }^{19}$. Os textos de comentadores versando sobre o papel do corpo na filosofia de Adorno assumem de forma não-crítica a posição do filósofo de que o corpo seria fonte dos desejos, como se a racionalidade não exprimisse, ela mesma, como dissemos acima, uma forma de desejo. Em seu livro inteiramente dedicado a essa temática da corporeidade em Adorno, Lisa Yun Lee identifica, em várias passagens, a dimensão somática e biológica a vários elementos que deveriam ser delineados em virtude de associações fantasísticas complexas, irredutíveis ao somático: "o corpo reúne sentimentos tais como desejo, luxúria, paixão e jouissance" (LEE, 2005, p.1); a história subterrânea do ocidente, "que foi recalcada, é a das pulsões, do desejo, do prazer e do sofrimento - em suma, uma história do corpo" (Idem, p.13); "cultivar a face sensual do próprio eu significa não recalcar as emoções, sentimentos e desejos do corpo" (Idem, p.33). Vemos aí uma relação dicotômica entre a racionalidade abstrata de um lado e a "corporeidade desejante" de outro, retirando de cena tudo o que poderia perfazer a esfera da teia fantasística do desejo inconsciente, que, de acordo com a linha interpretativa que seguimos, não se reduz ao somático, nem ao abstrato, cultural, linguístico. Do ponto de vista que defendemos, na verdade não é o corpo que deseja, mas o sujeito na medida em que é nutrido de fantasias in- e conscientes, de tal modo que toda excitação corpórea - até a sexualmente genital - é uma consequência da articulação fantasística do desejo como mediação entre o sujeito e a realidade; em outras palavras: não é em virtude de se estar excitado (genitalmente) que se deseja, mas o contrário: a excitação ocorre como resultado da articulação subjetiva do complexo desiderativo ${ }^{20}$. Ao ler criticamente Freud, J. Laplanche diz que a fonte da pulsão, ou seja, o lugar de onde provém a pressão que propele ao desejo, não é propriamente a zona erógena corporal - como havia dito Freud -, mas sim seu objeto, sua

19. Sobre esse tema da mediação inexpugnável da fantasia para o desejo, cf. Laplanche e Pontalis (1988).

20. Deve-se observar que essas expressões "em virtude de" e "resultado de" não implicam relação causal estrita, mas sim vínculos de antecedente/consequente bastante complexos. 
representação fantasística inconsciente, o que leva o psicanalista francês a dizer do objeto-fonte da pulsão (cf. LAPLANCHE, 1992b, pp.227-242).

Joel Whitebook, em várias passagens de seu importante livro Perversion and Utopia, apoiando-se na já citada ideia de Freud de que "pulsão" não é um conceito biológico, mas sim situado na fronteira do psíquico e do somático, aponta para a diferença nessa tripartição: o somático, que é não-linguístico; o inconsciente, que é pré-linguístico; e o consciente que é linguístico (distinção que ele diz ser ignorada por Habermas, uma vez que este, de forma semelhante a Lacan, teria assimilado o inconsciente à dimensão linguística) (WHITEBOOK, 1995, p.164ss.). Entretanto, ao comentar a temática da apropriação da psicanálise por Adorno, Whitebook não questiona em nenhum momento se o filósofo frankfutiano faz ou não justiça a essa dimensão intermediária do inconsciente. O próprio Whitebook usa a expressão (segundo pensamos, inadequada) "natureza interna" para indicar o que é da ordem do inconsciente (e portanto não-somático), mas não ficou atento às flutuações conceituais que o termo sofreu em seu livro (que a encaminham para o biológico), e - o que é mais importante para nós - nem se ela, ao ser empregada na Teoria Crítica, se refere ou não à corporeidade, ao somático, ao biológico. Nossa tese é de que, em toda a Dialética do Esclarecimento, a muito usada expressão "natureza interna" refere-se - de forma imprópria - à dimensão somática como sede do desejo, descurando todo o universo da rede de associações fantasísticas, fantasmáticas, imaginárias e das cargas de afeto que lhes são associadas. ${ }^{21}$ Assim, as leituras do significado do corpo na Dialética do Esclarecimento que associam dicotomicamente a materialidade supostamente "desejante" do corpo e a racionalidade abstrata, tomada como algo desprovido de desejo e de "vida”, como a de Lisa Yun Lee, não são equivocadas como apresentação do que Adorno e Horkheimer disseram, pois elas apenas testemunham o que vemos como calcanhar-de-aquiles na visão que estes têm do desejo de Ulisses - e, por extensão, de todo ser humano.

21. Embora não tenhamos espaço para argumentar aqui, nossa posição é de que a ideia de Adorno e Horkheimer de que o corpo sempre atrai como imagens socialmente mediadas (cf. DA 128) não é suficiente para solucionar este problema crítico que apontamos. Em nosso texto a que nos referimos antes (FREITAS, 2009), tocamos nessa questão, mas também não tivemos ainda a oportunidade de desenvolver nossa perspectiva, o que esperamos fazer em breve. 


\section{Freitas - 143 \\ REFERÊNCIAS BIBLIOGRÁFICAS²2}

ADORNO, Theodor W. Anti-Semitism and Fascist Propaganda. In: Soziologische Schriften I. Gesammelte Schriften, vol. 8. Frankfurt a. M.: Suhrkamp, 1997a, pp.397-407. . Bemerkungen über Politik und Neurose. In: Soziologische Schriften I. Gesammelte Schriften, vol. 8. Frankfurt a. M.: Suhrkamp, 1997b, pp.434-9.

. Dialektische Epilegomena. In: Kulturkritik und Gesellschaft, Gesammelte Schriften, vol. 10.2. Frankfurt a. M.: Suhrkamp, 1997c, pp.739-82.

. Freudian Theory and the Pattern of Fascist Propaganda. In: Soziologische Schriften

I. Gesammelte Schriften, vol. 8. Frankfurt a. M.: Suhrkamp, 1997d, pp.408-433.

. Minima Moralia. In: Gesammelte Schriften, vol. 4. Frankfurt a. M.: Suhrkamp, 1997e.

. Negative Dialektik. In: Gesammelte Schriften, vol. 6. Frankfurt a. M.: Suhrkamp, 1997 .

. Die revidierte Psychoanalyse. In: Soziologische Schriften I. Gesammelte Schriften, vol. 8. Frankfurt a. M.: Suhrkamp, 1997g, pp.20-41.

. Tesen über Bedürfnisse. In: Soziologische Schriften I. Gesammelte Schriften, vol. 8. Frankfurt a. M.: Suhrkamp, 1997h, pp.392-6.

. Zum Verhältnis von Soziologie und Psychologie. In: Soziologische Schriften I. Gesammelte Schriften, vol. 8. Frankfurt a. M.: Suhrkamp, 1997i, pp.42-92.

. Zur Lehre von der Geschichte und von der Freiheit. Frankfurt am Main: Surhkamp, 2006.

. Zur Bekämpfung des Antisemitismus heute. Vermischte Schriften I. Gesammelte Schriften, Frankfurt am Main: Surhkamp, 1997j, pp.36o-383.

ADORNO. Theodor W.; HORKHEIMER, Max. Dialektik der Aufklärung. Philosophische Fragmente. Gesammelte Schriften, vol. 3. Frankfurt a. M.: Suhrkamp, 1997.

AMARAL, Mônica G. T. O espectro de narciso na modernidade: De Freud a Adorno. São Paulo: Estação Liberdade, 1997.

ANDRÉ, Jacques. As origens femininas da sexualidade. Rio de Janeiro: Jorge Zahar Editor, 1996.

BAUM, Klaus. Die Tranzendierung des Mythos. Zur Philosophie und Aeshetik Schellings und Adornos. Würzburg: 1988.

BENHABIB, Seyla. Critique, Norm and Utopia. A Study of the foundation of Critical Theory. New York: Columbia University Press, 1986.

CASTORIADIS, Cornelius. L'institution imaginaire de la société. Paris: Éditions du Seuil, 1975.

COOK, Deborah. The culture industry revisited: Adorno on mass culture. Boston: Rowman \& Littlefield, 1996.

22. Considerando os limites de confecção desse texto, optou-se por listar apenas os itens mais relevantes e conexos à temática geral. 
. Adorno, Habermas, and the Search for a Rational Society. Londres: Routledge, 2004.

DUARTE, Rodrigo. A. P. Adornos. Nove ensaios sobre o filósofo frankfurtiano. Belo Horizonte: Editora UFMG, 1997.

. Mimesis e racionalidade. O conceito de domínio da natureza em Th. Adorno. São Paulo: Loyola, 1993.

. Sublimação ou expressão? Um debate sobre arte e psicanálise a partir de Theodor W. Adorno. In: Revista Brasileira de psicanálise. São Paulo: Associação Brasileira de Psicanálise, 1998, pp.319-336.

FISCHER, Karsten. “Verwilderte Selbsterhaltung”. Zivilizationstheoretische Kulturkritik bei Nietzsche, Freud, Weber und Adorno. Berlim: Akademie Verlag, 1999.

FREITAS, Verlaine. Tertium non datur. A dicotomia espírito/natureza na moral esclarecida e em sua crítica. In: TIBURI, Márcia \& DUARTE, Rodrigo (org.). Seis leituras sobre a Dialética do esclarecimento. Ijuí: Unijuí, 2009, pp.43-68.

. O dissonante e o demoníaco. A insuficiência do negativo na teoria estética e erótica de Marcuse. In: Herbert Marcuse: Dimensão Estética. Homenagem aos 50 anos de Eros e Civilização. Belo Horizonte: ABRE, 2007, pp.1-9

. Para uma dialética da alteridade. A constituição mimética do sujeito, da razão e do tempo em Theodor Adorno. Tese. Belo Horizonte, Inédito.

FREUD, Sigmund. Eine Kindheitserinnerung des Leonardo da Vinci. In: Gesammelte Werke, vol.VIII. Frankfurt a. M.: Fischer Verlag, 1999a, pp.127-211.

. Massenpsychologie und Ich-Analyse. In: Gesammelte Werke, vol.XIII. Frankfurt a. M.: Fischer Verlag, 1999b, pp.71-161 .

. Triebe und Triebschicksale. In: Gesammelte Werke, vol. Frankfurt a. M.: Fischer Verlag, 1999c, pp.209-231.

. Das Unbehagen in der Kultur. In: Gesammelte Werke, vol.XIV. Frankfurt a. M.: Fischer Verlag, 1999d, pp.419-505.

. Das Unbewußte. In: Gesammelte Werke, vol. Frankfurt a. M.: Fischer Verlag, 1999e, pp.263-303.

. Vorlesungen zur Einführung in die Psychoanalyse. Gesammelte Werke, vol. XI. Frankfurt a. M.: Fischer Verlag, 1999f.

GEYER-RYAN, Helga \& LETHEN, Helmut. Von der Dialektik der Gewalt zur Dialektik der Aufklärung, In: VAN REIJEN Willem \& NOERR, Gunzelin S. Verizig Jahre Flaschenpost: "Dialektik der Aufklärung" 1947 bis 1987. Frankfurt a. M.: Fischer, 1987, pp.41-72.

GHIRALDELLI Jr., Paulo. O corpo de Ulisses. Modernidade e materialismo em Adorno e Horkheimer. São Paulo: Ed. Escuta, 1996.

HABERMAS, Jürgen. Philosophische Discurs der Moderne. Frankfurt a. M.: Suhrkamp, 1985.

HEGEL, Georg W. Friedrich. Vorlesungen über Ästhetik. Frankfurt a. M.: Suhrkamp, 2001. 
HORKHEIMER, Max. Diskussionen über die Differenz zwischen Positivismus und materialistischer Dialektik. In: . Gesammelte Schriften, vol.12. Frankfurt a. M.: Suhrkamp, 1985, pp.436-58.

JAMESON, Fredric. Marxismo tardio. Adorno, ou a persistência da dialética. Tradução de Luiz Paulo Rouanet. São Paulo: Unesp \& Boitempo Editorial, 1996.

KANT, Immanuel. Kritik der Urteilskraft. Hamburg: Felix Meiner, 2001.

KIPFER, Daniel. Individualität nach Adorno. Tübingen: Francke, 1999.

LACAN, Jacques. Kant avec Sade. In: Écrits II. Paris: Éditions du Seuil, 1999, pp.243-69.

LAPLANCHE, Jean. A angústia. Tradução de Álvaro Cabral. São Paulo: Martins Fontes, 1998a.

. Freud e a sexualidade. O desvio biologizante. Tradução de Lucy Magalhães. Rio de Janeiro: Jorge Zahar Editor, 1997.

_. O inconsciente e o id. Tradução de Álvaro Cabral. São Paulo: Martins Fontes, 1998b. . Novos fundamentos para a psicanálise. Tradução de Cláudia Berliner. São Paulo: Martins Fontes, 1992a.

. Vida e morte em psicanálise. Tradução de Cleonice Paes Barreto Mourão e Consuelo Fortes Santiago. Porto Alegre: Artes Médicas, 1985. . La révolution copernicienne inachevée. Paris: Aubier, 1992b.

LAPLANCHE, Jean \& PONTALIS, Jean-Batiste. Fantasia originária, fantasias das origens, origens da fantasia. Tradução Álvaro Cabral. Rio de Janeiro: Jorge Zahar Editor, 1988.

. Vocabulário da psicanálise. Tradução de Pedro Tamen. São Paulo: Martins Fontes, 2000.

LASH, Scott. The Culture of Narcissism. New York: W. W. Norton, 1979.

LEE, Lisa Yun. Dialectics of the body. Corporeality in the Philosophy of T. W. Adorno. New York: Routledge, 2005.

MARCUSE, Herbert. Eros e civilização. Uma interpretação filosófica do pensamento de Freud. Tradução de Álvaro Cabral. Rio de Janeiro: Guanabara Koogan, 1996.

NHO, Soung-Suk. Die Selbstkritik und Retung der Aufklärung. Frankfurt a. M.: Peter Lang, 2000.

NOBRE, Marcos. A Dialética Negativa de Theodor W. Adorno. A ontologia do estado falso. São Paulo: Iluminuras, 1998.

RANTIS, Konstantinos. Psychoanalyse und "Dialektik der Aufklärung”. Lüneburg: zu Klampen, 2001.

RIBEIRO, Paulo Carvalho. O problema da identificação em Freud. O recalcamento da feminilidade primária. São Paulo: Escuta, 2001. 
146 - Remate de Males 30.1

ROUANET, Sérgio Paulo. Teoria Crítica e Psicanálise. Rio de Janeiro: Tempo Brasileiro, 2001.

STENDHAL (Henri-Marie Beyle). De L’Amour. Paris: Michel Levy Fréres, 1857.

VAN REIJEN Willem \& NOERR, Gunzelin S. (Orgs.) Verizig Jahre Flaschenpost: "Dialektik der Aufklärung" 1947 bis 1987. Frankfurt a. M.: Fischer, 1987.

WELLMER, Allbrecht. Zur Dialektik von Moderne und Postmoderne. Vernunftkritik nach Adorno. Frankfurt a. M.: Suhrkamp, 1981.

WHITEBOOK, Joel. Der gefesselte Odysseus. Studien zur Kritischen Theorie und Psychoanalyse. Frankfurt a. M.: Campus Verlag, 2009. . Perversion and Utopia. A Study in Psychoanalysis and Critical Theory. Cambridge: The MIT Press, 1995. 